\title{
Imagens do futuro
}

\section{Risco e responsabilização na gerência neoliberal do amanhã}

\author{
Claudia Linhares Sanz* \\ https://orcid.org/0000-0003-0256-817X \\ Mirella Pessoa** \\ https://orcid.org/0000-0002-7194-4186
}

Futuro: dispositivo contemporâneo do poder

Esteja avisado: o aplicativo Future You Simulation foi projetado para aterrorizar. Ele mostra aos usuários como eles envelhecerão no futuro, antes de dar algumas dicas úteis sobre como manter um brilho jovem. Reportagem publicada no jornal inglês DailyMail.com (Palmer, 2019)1

- Saltaste sem paraquedas?!

- Tranquilo, resolvo isso depois!

- Como "depois"? Isso é como se preocupar com sua pensão quando estiver para se aposentar.

- Aposentadoria? Não... Falta muito para isso! - Não nos diga que estás sem um sistema de pensão.

- Não... Agora estou jovem.

- Isso você pensa agora. Mas você chegará em uma idade em que já não poderá mais trabalhar [...]

- Mas isso me custa, não?

- Sim, mas seu futuro vale! Quanto pagarias agorinha por um paraquedas?

Propaganda do Sistema Nacional de Pensões, Peru, $2015^{2}$

* Universidade de Brasília, Brasília, Brasil.

** Universidade Federal de Pernambuco, Recife, Brasil.

1. "A inteligência artificial vai dizer como seu rosto envelhecerá [...]. O aplicativo pode analisar sua pele a partir de uma selfie e mostrar como você será em vinte anos." (Palmer, 2019). Nessa e nas demais citações em idioma estrangeiro, a tradução é nossa.

2. Parte da campanha da Oficina de Normalization Previdencial (ONP), organismo público especializado do setor de economia e finanças do Peru, vinculado ao Sistema Nacional de Pensões (sNP). Campanha disponível em: <http://bit.ly/2UHmASD>, consultado em 13/2/2019 (oNP, 2015). 
Ver seu rosto transformado pelas marcas do tempo na tela do celular é a principal promessa do aplicativo Future You Simulation. A partir de algoritmos treinados para reconhecer as áreas da face que têm maior probabilidade de mudar à medida que envelhecem, oferece ao usuário uma simulação pretensamente acurada do que o espera. O programa mostra como você será em vinte anos, caso não adote as orientações de cuidados com a saúde fornecidas pelo aplicativo (Palmer, 2019). Trata-se de um futuro tão previsível quanto amedrontador. Algo, entretanto, que não se restringe às paranoias contemporâneas da beleza perfeita e eterna, nem a aplicativos “caça-níqueis" como esse. Em narrativa cada vez mais global, de campos sociais diversos - jornalismo, publicidade, medicina, economia, estatística e educação -, o futuro integra nosso cotidiano a partir de imagens pretensamente cada vez mais nítidas. Projeções econômicas, previsões estatísticas, imagens neurocientíficas, exames genéticos, simulações eletrônicas - uma vasta gama de figuras circula no mundo contemporâneo anunciando que os riscos do porvir podem e devem ser mapeados. Trata-se de uma superabundância imagética acerca do futuro - sustentada pelas tecnologias de antecipação e de simulação - que entrelaça uma generalização da cultura do risco à privatização de sua gestão ${ }^{3}$.

Atuando como uma espécie de máquina na biopolítica dos possíveis, o futuro contemporâneo exige progressivas estratégias e múltiplos dispositivos de segurança que devem, na lógica neoliberal, ser responsabilidade especialmente individual. Máquina biopolítica dos possíveis porque, fazendo funcionar certas relações com o tempo presente e com o que está por vir, acaba por constituir uma economia do que é (ou não) provável, do que pode ser (ou não) realizável, do que deve (ou não) ser considerado temível ou imaginável. Faz girar assim uma racionalidade cuja lógica garante certa maneira de lidarmos com nossas expectativas e com a virtualidade do tempo vindouro. Máquina que não está localizada em uma ou em outra instituição, mas que se multiplica em diagramas, estratos e inscrições contínuas e mínimas. Atravessa o campo social penetrando também a relação do sujeito com ele mesmo, com suas esperanças ou medos, com o que imagina que pode vir a ser, enquanto indivíduo e ator social. Máquina biopolítica mas não porque está restrita à dimensão biológica da vida, não porque se limita ao jogo de variáveis de nascimento e morte, saúde ou doença; e sim porque governa a vida em sua complexidade, relacionando-se também com seu nível molecular, atuando na vida íntima das pessoas, em suas

3. Vale ressaltar duas linhas de análise importantes no debate acerca do risco: a primeira entrelaça o risco a uma abordagem sociológica e a fenômenos como mudanças climáticas e desastres ecológicos (Beck, 2010, e Giddens, 2009, por exemplo); a segunda articula a análise do risco à ideia de governamentalidade proposta por Foucault, entendendo o risco como forma específica de governo (Defert, 1991; Ewald, 1991; O’Malley, 1996; e Rose, 1989). 
opções e escolhas cotidianas, em seus projetos pessoais, vinculando-se com o que cada um estima como chance de sucesso e com os modos como calcula potencializar suas habilidades ou evitar sua vulnerabilidade ${ }^{4}$.

De fato, todos nós (não só os usuários do Future You Simulation) estamos lidando, uns mais outros menos, cada vez mais com simulações visuais do que nos tornaremos um dia. Estamos imersos em um senso de futuro que antecipa o campo do porvir, simula seus perigos e exige a administração cada vez mais pessoal dessas ameaças. Diante das ameaças, estamos como na propaganda de previdência peruana usada na epígrafe: como alguém que salta de um avião, somos capazes de avistar o porvir. Diante dele, entretanto, entramos em queda livre, caindo no vácuo sem resistência, em direção à inevitável colisão com o solo. Resta, a cada um, ser ágil e rápido, e lançar mão de seu próprio paraquedas.

Trata-se da instalação de um senso de futuro que se afasta, em vários aspectos, daquele vivido em outros (futuros) passados. Fenômeno histórico, de ordem global, que não apenas atua na amplitude de nossos projetos políticos - ou na falta deles -, mas que tem também efeitos capilares no cotidiano do sujeito contemporâneo. Não por acaso, o futuro contemporâneo aparece constantemente monetizado: ele vale (e não qualquer coisa, como trata a propaganda peruana). Vale, sobretudo, a administração das condutas, individuais e coletivas; a gerência do corpo; a orientação da formação pedagógica; o controle dos prazeres; o aumento da capacidade de resiliência. Como percebeu Agamben, “o futuro, bem como a crise, é hoje um dos principais e mais eficazes dispositivos do poder"”.

De que maneira, porém, uma dimensão como o futuro - que ainda não existe propriamente - pode atuar hoje como dispositivo? Provavelmente porque mobiliza em torno de sua expectativa um conjunto heterogêneo de forças, engrenagens, práticas,

4. A categoria foucaultiana de biopolítica se refere aqui ao complexo processo que faz com que a vida e seus mecanismos entrem no domínio dos cálculos explícitos do poder, tornando o homem moderno “um animal, em cuja política, sua vida de ser vivo estão em questão" (Foucault, 1988, p. 156). Cabe, entretanto, lembrar que ao longo da obra de Foucault esse conceito ganha amplitude própria, sendo, então, pensado a partir do conceito de governamentalidade, encontro das técnicas de dominação exercida sobre os outros e as técnicas de si (Foucault, 2008a). Assim, questões como saúde, higiene, longevidade, nascimento e raça são integradas à análise da razão governamental e do seu nível molecular que organiza e pauta a conduta individual (ver Foucault, 2008a, 2008b, 1999; Castro-Gomez, 2010). Nesse sentido, importante ressaltar aqui que esse tipo de poder que Foucault chamou de biopoder é produtivo também em termos de temporalidade: ele pressupõe certo ritmo temporal, institui certa experiência de cálculo e de previsão e, sobretudo, trabalha instaurando o risco como elemento crucial dos modos de governar que se instalaram desde a modernidade e que, já há algum tempo, adquirem lógicas neoliberais (ver Sanz, 2019a, e Pessoa, 2020).

5. Intervenção de Agamben no programa Chiodo Fisso da rádio Rai 3, em 25/1/2019. Disponível em <http://bit.ly/2WmLRPi>, consultado em 3/5/2019. Sobre dispositivo, ver Agamben (2009) e Deleuze (1996). 
discursos, saberes e imagens, trabalha fabricando o presente. Alavanca certas ações; legitima forças sociais, neutraliza outras; atribui sentidos ao real; dá corpo a uma racionalidade política e invalida outras; exige medidas de segurança e dispositivos de vigilância; opera regulando políticas públicas do mesmo modo que orienta decisões íntimas. Assegura certos gestos e modos de proceder coletiva e individualmente. Produz certa distribuição de olhares que, aliás, não vislumbra só o que virá. Assim, o futuro não é apenas uma ideia que reflete um modelo produtivo de poder, mas um dispositivo produtivo desse modelo mais amplo.

Não tratamos, decerto, do futuro propriamente, mas de determinado modo de experimentar essa dimensão abstrata que, historicamente, se altera e se transmuta (Sanz, 2019b). É em cada atualidade que, entrelaçado aos jogos de poder, um certo senso de futuridade emerge ${ }^{6}$. Longe de ser apenas um tipo de imaginação que se desdobra exclusivamente em narrativas ficcionais, é também uma imaginação política, que paira, legitima e sustenta verdades que, por sua vez, garantem leis e normas. Senso capaz de orientar (ou excluir) investimentos financeiros na ciência e na pesquisa; justificar ementas governamentais, determinar a emergência (ou a escassez) de lutas sociais. Sentimento de tempo, presente nos assuntos popularizados na mídia e nos modos como os idosos compram seguros de vida (ou na frequência com que os jovens abandonam a escola). Algo que possibilita novas expectativas para a infância, implica certos desafios para a juventude e gera suas próprias acepções para a velhice. Sentimento não apartado dos modos de governança de uma certa racionalidade; dos conflitos e disputas econômicas; das visibilidades e invisibilidades; dos saberes de uma época. Senso que se instala nas (e pelas) imagens ${ }^{7}$.

De fato, não é coadjuvante o estatuto do atual regime de visibilidade na constituição de nosso senso contemporâneo de futuro ${ }^{8}$. Se o porvir como dimensão imaginativa parece hoje eclipsado, pelo menos em alguns sentidos, tal atrofia não

6. Cabe ressaltar, dentre as análises que investigaram os enquadramentos históricos do senso de futuridade, a obra do historiador alemão Koselleck, Futuro passado (2006), que se tornou obrigatória no debate acerca do futuro. Na esteira de Koselleck, outros pensadores mapearam as formas históricas do futuro - tanto as passadas como as atuais -, entre eles Hólscher (2014), Hartog (2013) e Minois (2016). Mais recentemente, no âmbito das análises da alteridade do senso contemporâneo de futuro, citamos os estudos de Nowotny (1994), Adam e Groves (2007), Rosa (2019) e Urry (2016).

7. Sobre o laço estreito entre imagem e futuro vale lembrar o estudo seminal do sociólogo holandês Polak, The image of the future, publicado em 1955. Segundo o autor, as imagens estão intimamente relacionadas com os conceitos de tempo que o homem realizou: "todas as imagens do futuro que levam o homem para fora e para além dele também contêm um conceito de tempo que está fora e além do tempo existente" (1973, p. 7).

8. Um regime de visibilidade "consiste, antes, não tanto no que é visto, mas no que torna possível o que se vê. Dessas condições de visibilidade participam máquinas, práticas, regras, discursos que estão articulados a formações de saber e jogos de poder" (Bruno, 2013, p. 15). 
acontece sem uma profusão discursiva realizada, sobretudo, a partir das imagens. São as imagens cada vez mais nítidas da antecipação que ancoram uma espécie de hipervisibilidade da qual não escapa nem o futuro. Na "tela total" da atualidade, usando figura de Baudrillard (1991), também a vida por vir se presentifica por uma espécie de continuidade temporal sem fissuras ou alteridade, como imagem sem enigma, mistério ou face oculta, sem fora ou linha de fuga. Pelo contrário: nessa narrativa continuamente proferida pelos jornais ou pelas propagandas das novas escolas da elite internacional, pelos anúncios de fundos de pensões para idosos ou pelo marketing das reformas governamentais, brasileiras e mundiais, o futuro aparece como quadro já fixado, impresso de antemão; como tabelas já preenchidas com números - semelhantes aos algoritmos do aplicativo que nos fazem ver o invisível do tempo em nosso próprio rosto e feição.

É justamente no estreitamento do sentido do possível que as tecnologias imagéticas parecem trabalhar hoje: nítido e atual, o futuro vai perdendo graus de incerteza, virtualidade e imprevisibilidade, tendo subtraídas de sua figura aberturas e invisíveis. Funcionando como as smart câmeras, aquelas que pretensamente possibilitam à vigilância intervir pró-ativamente antes do crime, as atuais tecnologias imagéticas são máquinas de ver também o destino, configuradas sob a égide da especulação, da predição e da prevenção. São simultaneamente máquinas de discursar a respeito de nosso destino - como os aplicativos que nos oferecem as fotografias das ruínas de nosso envelhecimento (Sanz e Pessoa, 2020). Como analisaremos neste artigo, trata-se de um regime de visibilidade que distribui claros e escuros acerca do porvir, faz ver algumas imagens e ofusca outras. Regime que sustenta uma certa gerência do futuro - algo que alia a produção de uma cultura da antecipação tanto à responsabilização do indivíduo quanto a uma espécie de apatia social generalizada.

Domínio do que se manifesta no amanhã: pronto para ler o futuro e fazer parte dele?

Are students ready for the future? Slogan do XQ Super School Project, EUA, $2015^{9}$

Todas as empresas estão na mesma corrida: encontrar um exame único que permita detectar qualquer tipo de tumor que se manifeste no futuro.

Rocío Arroyo, diretora da Amadix, em entrevista ao El País (Ariza, 2019)

9. Propaganda de divulgação do xe Super School Project The Future of Our Schools: An Urgency For Change, de 2015. Disponível em <http://bit.ly/2GiHfo4>, consultado em 11/4/2019. 
A medicina contemporânea tem investido fortunas no diagnóstico preventivo, direcionando esforços para antecipar e controlar doenças como, por exemplo, as oncológicas. Como anuncia Baumgartner (2019) em reportagem publicada em El País, a empresa Amadix - pequena startup de biotecnologia - abre uma nova era na previsão do câncer ao detectar tumores no cólon de pessoas saudáveis; o colofast ${ }^{10}$ poderá significar grande alívio para uma sociedade assombrada por essa epidemia contemporânea; uma vantagem abissal na corrida contra o câncer (pelo menos para quem puder pagar por ele). Mais do que isso, ter domínio daquilo que "se manifesta no futuro", segundo a pesquisadora de farmacologia experimental, não é só privilégio de quem tem acesso à medicina avançada; é também significativa vantagem econômica da Armadix no mercado diagnóstico preventivo, disputadíssimo pelos gigantes da indústria farmacêutica.

Quem não gostaria de estar livre da ameaça de vir a se tornar paciente de câncer ou de qualquer outra doença? Ou de tratá-la antes que ela se torne atual? Longe de ser simplesmente "criticável", o gesto de "dominar aquilo que se manifesta no futuro" se tornou uma lógica reguladora da sociedade contemporânea, algo, aliás, não restrito à medicina. A emergência desse tipo de analítica do futuro como operante imprescindível à sociedade e ao indivíduo coincide com a consolidação de uma arquitetura temporal generalizada, cujas lógicas são sobretudo econômicas. Nesse sentido, antes de se tornar ou o funcionamento estrutural da biomedicina ou argumento para as lutas ambientais, esse modo de antecipação do porvir participa de um processo amplo em que o modelo econômico é desdobrado e vertido em um modelo de "relações sociais, um modelo de existência, uma forma de relação consigo mesmo, com o tempo, com seu círculo, com o futuro" (Foucault, 2008a, p. 332). Nesse contexto, a temporalidade que pressupõe os diagramas oferta/procura, investimento/custo/lucro, financeirização/juros, especulação/antecipação, gestão/ capital humano passa a atravessar, valorar e significar todo o tecido social e também nossa existência, em níveis capilares.

A área ou o indivíduo que estiver em condições de prever, simular e anunciar os acontecimentos futuros adquire vantagem indiscutível na luta pela sobrevivência (e pelo poder). Da medicina à economia financeira, da educação ao mercado de trabalho - inúmeros são os investimentos no sentido de desenvolver "ferramentas de previsão", "sistemas de antecipação" ou "premissas antecipatórias" que deverão, segundo especialistas de diversas áreas, balizar atuais tomadas de decisão ${ }^{11}$. Não por

10. Primeiro exame de sangue capaz de detectar um tumor de cólon antes que ele se desenvolva.

11. Os future studies contemporâneos coroam a trajetória histórica de um campo de estudos que emerge na segunda metade do século xx (ver Bell, 1997; Amara, 1974). Desde então, o campo se tem desdobrado em abordagens e perspectivas variadas, tanto nas ciências humanas quanto nas biológicas e 
acaso, desde 2012 a Unesco catalisa suas ações prospectivas para o desenvolvimento do que denominou future literacy ${ }^{12}$. Em tradução literal, o nome desse projeto, realizado por meio da Rede Global de Alfabetização de Futuros ${ }^{13}$, significa “alfabetização futura”. Claramente, a expressão não se refere a uma alfabetização a se realizar no futuro; antes, versa acerca de pretenso letramento (em tradução mais precisa) em futuro, como se o porvir estivesse escrito e nos fornecesse sinais que precisam ser adequadamente interpretados, narrados e, sobretudo, usados de modo competente. Estar letrado em futuro, para Riel Miller (2018, p. 15), coordenador desse projeto internacional, significa ter adquirido uma nova habilidade: "alguém alfabetizado em futuro adquiriu as competências necessárias para decidir por que e como usar sua imaginação para introduzir no presente o futuro inexistente".

Segundo Roumiana Gotseva, consultora da Unesco, fundadora e diretora do Centro de Prospectiva Estratégica ${ }^{14}$, antecipação é a capacidade de habitar uma terra desconhecida e, simultaneamente, perceber as diferentes maneiras pelas quais estamos olhando para ela ${ }^{15}$. Certamente Gotseva não está errada: a cultura da antecipação nos faz viver um regime temporal em que o tempo que habitamos está, por um lado, "fora de qualquer lugar" (nem lá, nem aqui); por outro, sempre aqui - já que "digere” o amanhã e dele retira seu caráter de alteridade. Isso significa que a dimensão do futuro é causa projetada, convocada a integrar - como simulação - nosso presente e, assim, torna-se habitável (sem ser). Constantemente convocado a ser lido, o futuro também

exatas. Articulando cientistas e pensadores de áreas interdisciplinares, essas pesquisas se têm ocupado em criar sistemas de análise de probabilidade, regras estatísticas de prognósticos, métodos de prevenção, dando suporte, atualmente, para diferentes instituições governamentais, agências de inteligência, agências internacionais como a Unesco ou, simplesmente, para alimentar o mercado.

12. Ver a respeito "Futures Literacy", Unesco.org, <http://bit.ly/2GpjMQV>, consultado em $12 / 4 / 2019$.

13. Nos últimos anos, cátedras Unesco em alfabetização de futuros foram iniciadas na Finlândia, Grécia, Itália, Malásia, Holanda, Tunísia, Reino Unido e Uruguai. Elas são "catalisadores para o desenvolvimento dos Centros de Alfabetização de Futuros e peças-chave de uma emergente Rede Global de Alfabetização de Futuros". Planos em andamento visam a cadeiras no Chile, França, Marrocos, Tailândia etc. Disponível em: <http://bit.ly/2GpjMQV>, consultado em 12/4/2019.

14. Com sede na Bulgária, presta consultoria "voltada para o futuro", dedicada à previsão governamental, corporativa e social. Como essa empresa, há, ressalte-se, um pool de novas empresas emergentes nesse contexto, como a Foresight Alliance, que aplica "previsão, estratégia e pesquisa para desenvolver a resiliência das organizações no ambiente cada vez mais complexo e em rápida mudança de hoje" (disponível em: Foresight Alliance, <http://bit.ly/2UrAFzk>, consultado em 5/5/2019), ou a Rohrbeck Heger, que convida seus clientes a descobrir "o que impulsionará o futuro do seu negócio" e a preparar "estratégias ágeis para se beneficiar da mudança” (Rohrbeck Heger, 2014, disponível em <http://bit. ly/2KKwPS5>, consultado em 5/5/2019).

15. Em depoimento para o vídeo de divulgação do livro publicado pela Unesco Transforming the Future: Anticipation in the 21st Century. Disponível em <http://bit.ly/2GfUS7k>, consultado em 5/5/2019. 
deve ser usado, como ensinam os mais de quarenta Futures Literacy Laboratories (FLL) ${ }^{16}$ da Unesco, espalhados pelo mundo.

Não por acaso, esses sistemas de antecipação dão base à gestão social das populações e à elaboração de estratégias fundamentais da sociedade, como se pode verificar no relatório do Centro Europeu de Estratégia Política (EPSC, 2016). Escrito por especialistas convidados pela comissão da União Europeia, afirma que os jovens europeus apresentam deficit pedagógico em relação ao futuro: segundo eles, embora muitos jovens em toda a Europa possuam boas qualificações formais, demonstram considerável deficiência nas competências cognitivas e não cognitivas básicas, "capital mais importante para o mundo do trabalho à nossa frente" ${ }^{17}$. Também não é raro ouvirmos indagações como a da campanha publicitária do XQ Super School. Mobilizando centenas de escolas, professores, alunos e fundos, o projeto indaga: “estaríamos prontos para o futuro?", em slogan que naturaliza a convicção de que o futuro já é conhecido e, sobretudo, incompatível com os processos pedagógicos atuais. Questionamento semelhante foi feito pelo The Guardian a seus leitores: "você está pronto para fazer parte do futuro?" (Niemtus, 2019). De acordo com a reportagem, os trabalhos do amanhã nos atropelarão caso não estejamos prontos para nos adequar e tornar nossas carreiras "à prova do futuro". De fato, expressões como "carreiras do amanhä" (EPSC, 2016) ou "futuro do trabalho" 18 , presentes em reportagens, campanhas de marketing, relatórios científicos ou inúmeros diagnósticos sociais, dão corpo e intensificam a implantação dos sistemas de antecipação como um programa geral da cultura da antecipação que, chancelada por áreas distintas, se impõe como o único modo adequado e seguro de administrar a vida.

De certo, antecipação e especulação se tornaram atos imprescindíveis à sobrevivência individual em um mundo em que crédito, investimento, endividamento e risco já não se restringem às transações financeiras. Utilizamos também essa métrica ou "critérios" (todos de cunho bastante temporal) para avaliar se devemos nos divorciar, ter filhos ou, simplesmente, se devemos fazer o "investimento" no último cosmético do mercado. Eles também atravessam, por exemplo, aplicativos como Future You Simulation, que exibem riscos em imagens de rostos envelhecidos e, em seguida, uma série de investimentos necessários para os cuidados com a pele enquanto ela ainda

16. A tarefa dos Futures Literacy Laboratories (FLL) da Unesco é alfabetizar (em futuro) milhares de pessoas que, então, se tornarão "empoderadas para realizar seus próprios projetos, com suas próprias abordagens, aprimorando os sistemas de antecipação”. Disponível em: <http://bit.ly/2GpjMQV>, consultado em 12/4/2019.

17. "A criatividade, a inteligência emocional e as competências transversais constituem, sem dúvida, o que fará a diferença no futuro" (EPSC, 2016, p. 8).

18. We examine emerging models and ask what's to celebrate, what's to fear. Disponível em: $<\mathrm{http}: / / \mathrm{bit}$. ly/2G7GDAh>, consultado em 11/4/2019. 
permanece jovem. Trata-se de um modo social de como nos relacionar com o tempo vindouro próprio da racionalidade neoliberal; racionalidade que, como tal, "tende a organizar e a estruturar não apenas a ação dos governantes, mas até a conduta dos governados" (Dardot e Laval, 2016, p. 17).

Curioso notar que, nesse jogo de afetos, o desenvolvimento dos sistemas de antecipação e identificação dos riscos não está necessariamente vinculado à ação política e social. Wallace-Wells (2019), em artigo no The New York Times, retrata de modo sintomático essa articulação da retórica do medo como mobilizador de uma urgência e, ao mesmo tempo, sintoma de gigantesca imobilização. Em sua manchete, a constatação: “Tempo de pânico, o planeta está ficando mais quente de maneira catastrófica. E o medo pode ser nossa única salvação”. De acordo com seu texto, a letargia diante dos anúncios de catástrofe se daria por uma reticência vinda, às vezes, do próprio campo científico, que não torna as previsões suficientemente aterrorizantes para que, de fato, nos protejamos desse futuro pronunciado. Seria preciso agora sermos mais enfáticos: "o pânico pode parecer contraproducente, mas no ponto em que estamos o alarmismo e o pensamento catastrófico são valiosos, por várias razões" (Wallace-Wells, 2019).

Curioso e trágico, o artigo não é mero grito de desespero diante das negativas sucessivas dos governos e das instituições internacionais para modificar o que envenena e mata nosso planeta. É também sintoma de que parecemos todos surdos (ou cínicos) diante do alarme de colapso ambiental. Mais do que isso: sintoma de uma imobilidade e de uma apatia política que não são simples decorrência da pouca intensidade de terror. São antes consequência de processo bem mais amplo, ligado à instalação dessa racionalidade da qual tratamos aqui. Racionalidade que não pode renunciar às constantes ameaças, mas que as mantém funcionando no âmbito de uma grade de interpretação em que se tornam visíveis e "minimizáveis" sobretudo aqueles riscos que pretensamente devem ser administrados individualmente. Assim, por um lado, essa inflação de perigos, essa insegurança generalizada é condição de possibilidade para a instauração de múltiplos dispositivos de segurança: imprescindíveis para legitimar as constantes crises necessárias à gerência neoliberal. Por outro, tais crises e riscos (inclusive os ambientais) são apartados do âmbito social, esvaziados de dimensão política e divorciados dos dispositivos coletivos: esses devem ser enfraquecidos e vertidos - como discutem Dardot e Laval (2016, p. 349) - em crises individuais, em riscos ligados à existência, como veremos a seguir. 
Risco na governança neoliberal: privatização do destino e exigência de resiliência

\author{
As conquistas da era industrial e da informação estão moldando um mundo futu- \\ ro que é mais perigoso e mais rico em oportunidades do que nunca. \\ Global Trends: Paradox of progress, Us, $2017^{19}$ \\ É a liberdade que você queria para decidir o seu futuro.
}

Propaganda da Campanha da Reforma do Ensino Médio (MEC, 2017).

Para Foucault (2008a), a arte de governar do liberalismo do século XIX seria responsável por gestar as liberdades e calcular (e gerir) os perigos que podem interferir na organização das possibilidades graças às quais podemos ser livres. No neoliberalismo, tal cálculo é tarefa, sobretudo, do sujeito. Por isso os "riscos calculados" devem ser assumidos desde a infância, como aparece na publicidade da Escola Concept, instituição da elite paulistana. Os produtos de comunicação das escolas dos "líderes do futuro", aliás, promovem de modo eficiente a moral neoliberal: neles, os cálculos acerca dos riscos aparecem como habilidade imprescindível ou item valioso dos currículos milionários e são tratados como o único critério verdadeiramente eficiente para as escolhas a realizar ao longo das jornadas individuais. Trata-se, segundo Dardot e Laval (2016), de um modo totalizante de monetizar decisões e privatizar condutas, utilizando para isso o princípio da "liberdade de escolha", importante engrenagem de funcionamento dessa lógica. Nessa perspectiva, enfatizam e intensificam a narrativa hegemônica em que o indivíduo é o "único responsável por seu destino", e, assim, “a sociedade não lhe deve nada” (Dardot e Laval, 2016, p. 213). Em contrapartida ele deve aprender - de preferência nas escolas mais caras do planeta - a mostrar constantemente seu valor, sobretudo na gerência eterna dos riscos, nos cálculos de perdas e ganhos, para, de fato, ter acesso ao bem-estar ou, ainda, merecer condições de existência.

É sintomático de nossa época o fato de as existências estarem vinculadas a essa capacidade de administração de gerência das ameaças do futuro, desde as fases iniciais da vida: "as crianças precisam aprender a assumir responsavelmente seus riscos e como se tornar arquitetos de sua própria jornada" 20 . Trata-se de ubiquidade das ameaças em diversas etapas e âmbitos da vida que naturalizam a ideia de que viver é, mais do

19. Global Trends é a "avaliação estratégica" produzida a cada quatro anos, desde 1997, pelo Conselho Nacional de Inteligência (NCI) americano, que visa a "mapear as principais tendências e incertezas que podem moldar o mundo nos próximos vinte anos e ajudar líderes seniores dos Estados Unidos a pensar e planejar a longo prazo". Paradox of progress foi o título do relatório de 2017. Disponível em <https://bit.ly/2YaDbPK>, consultado em 27/4/2020.

20. Campanha institucional de 2018 da Escola Concept intitulada Digital Fluency, disponível em: <https://bit.ly/2X2NC5h>, consultado em 13/2/2019 (Escola Concept, 2018). 
que tudo, administrar individualmente os perigos, fazendo (sempre que possível) a melhor escolha. Não por acaso, a publicidade da reforma brasileira do ensino médio, aprovada no Brasil no início de 2017 (Senado Notícias, 2017), também condiciona uma espécie de "ingresso" no futuro promissor às escolhas individuais realizadas pelos jovens. Segundo a propaganda, a reforma ofereceria aos estudantes "a liberdade que você sempre quis para decidir o seu futuro" 21 . Implicitamente, a "livre escolha" dos jovens estudantes parece não só entregar em suas mãos a decisão de quais matérias vão cursar durante os próximos três anos, mas torná-los cientes de que essas escolhas abrirão ou não as portas do almejado mercado de trabalho.

Se a educação contemporânea recalibra as promessas que faz à infância e à juventude, também as reformas previdenciárias vão ser efeitos-instrumentos dessa privatização das condutas. Embalada pela retórica neoliberal de autonomia, a velhice da população aparece como ameaça à sustentabilidade financeira das economias nacionais e acaba por servir de argumento para reformas que diminuem ainda mais o papel do Estado na gestão dos perigos atuais e também daqueles que estão por vir. Nada surpreendente, portanto, que a adaptação dos sistemas de pensão de aposentados apareça nas narrativas hegemônicas como um imperativo: o "mundo precisa repensar a aposentadoria” - avalia Robertson (2018) no The New York Times. Segundo ela, países como o Brasil teriam sistemas de pensão generosos demais, custeando "cerca de $70 \%$ do salário final do trabalhador", o que agravaria significativamente "a crise de dívida da nação" (Robertson, 2018). De acordo com o Banco Mundial, informa a reportagem, tal sistema não seria sustentável financeiramente.

Recentemente, o governo Bolsonaro, em sua campanha pela reforma da previdência, propôs que o país adotasse um regime de capitalização no lugar do "velho" sistema de repartição, "uma espécie de poupança que o próprio trabalhador faz para assegurar a aposentadoria no futuro" 22 . No sistema de capitalização, a aposentadoria do trabalhador passaria a ser individual, fazendo minguar paulatinamente o modelo solidário e coletivo de um fundo comum e administrado pelo Estado. Mesmo tendo sido retirado da reforma aprovada em 2019, tal sistema foi defendido em discursos amplamente midiatizados, circulando como modelo exemplar da dinâmica de desresponsabilização social e dissolução da força das coletividades. Pela promessa da "nova previdência", assim chamada na campanha institucional do governo ${ }^{23}$, os

21. Disponível em: <http://bit.ly/2GhvJsQ>, consultado em 11/4/2019.

22. "Reforma da Previdência: proposta do governo incluirá capitalização, diz Paulo Guedes" (G1, 2018). Disponível em <https://glo.bo/2UcSPo6>, consultado em 5/5/2019.

23. Os discursos governamentais defendiam a necessidade de atualização de um sistema que já não mais se encaixa nos modelos atuais do século xxi para algo "mais equilibrado", garantia de que "benefícios não consumam recursos que poderiam ir para saúde, educação e segurança”. "Proposta da Nova Previ- 
jovens poderiam contribuir financeiramente por meio de uma conta pessoal, o que daria mais "autonomia" para decidir individualmente como "seu dinheiro deverá ser investido" ${ }^{24}$. De fato, a ideia de capitalização da previdência social configura uma imagem emblemática da individualização do risco, fazendo com que cada um de nós conte cada vez menos com formas de ajuda mútua de nossos meios de pertencimento e com mecanismos públicos de solidariedade (Dardot e Laval, 2016, p. 348).

Cabe lembrar que a "liberdade" para decidir o próprio futuro (na infância, na juventude ou na velhice) se articula ao cultivo de certas capacidades que vão além de “correr riscos calculados". Não basta "ler" o futuro; é necessário ser resiliente diante das ameaças e dos riscos. Conceito derivado da ecologia e ligado à preservação dos recursos naturais, a resiliência - cooptada pelas práticas neoliberais - passa a ser pensada como uma espécie de ingrediente essencial a um sujeito capaz de se adaptar às crises (e mesmo assim traçar seu próprio futuro). Nesse processo, o conceito passa a ser aplicado à sociedade, à economia, aos planos de vida, sucessos e fracassos dos sujeitos. Isso significa, curiosamente, que os desastres, as mudanças ou o sofrimento implicado nas crises tornam-se mais do que simples ameaça ao desenvolvimento daqueles que aspiram à segurança: transformam-se em verdadeiras oportunidades de desenvolvimento (Reid, 2012). Nessa virada, a exposição ao desastre e aos riscos é tomada em termos positivos; chance de superação e nova autorregulação, abertura para transformação. Em consequência, como avalia Christian Dunker (2015), também o sofrimento se torna "uma espécie de força produtiva, uma espécie de núcleo psicológico do neoliberalismo" 25 .

De fato, o modus operandi desse sujeito empreendedor e resiliente se estrutura a partir de uma plataforma temporal bastante explícita: não apenas porque a otimização de si mesmo requer dinamismo, rapidez e permanente atualização. Estar cada vez "mais ótimo", adaptar-se às permanentes crises constituem performances que exigem permanentemente antecipação no tempo, tanto para mapear as ameaças do que virá e criar estratégias de enfrentamento e minimização dos riscos, quanto para verter tais ameaças em motivos de fortalecimento e oportunidade de êxito e

dência é melhor para o Brasil". Site oficial do governo federal brasileiro. Disponível em: <http://bit. ly/2t21C4K>, consultado em 25/4/2020.

24. O secretário de Previdência do Ministério da Economia, Leonardo Rolim, informa que "o trabalhador poderá escolher, entre as instituições autorizadas, como os seus recursos seriam aplicados” (Martello, 2019).

25. "O neoliberalismo inventa um sofrimento produtivo, inventa uma inculcação de que cada empresa e cada indivíduo que se subjetiva como uma empresa têm que gerir o seu sofrimento de forma a torná-lo o mais produtivo possível. Ou seja, mesmo patológico, mesmo aquilo que seria mais desviante, mesmo aquilo que deveria nos indignar é tornado, por esse sistema, uma espécie de motor impulsionador para aquilo que seria assim no espírito do capitalismo." (Dunker, 2016). 
vitória. Regulado pela disputa constante com os demais e consigo, o sujeito vê-se diante do imperativo de investir em seu capital, calcular perigos, prever resultados, aplicar créditos, visar sempre a novas metas (sejam relativas à formação profissional, à saúde ou às finanças). O risco é, então, uma espécie de ambiência própria do empreendedorismo e da resiliência, necessária para que a empresa (como modo de subjetividade) seja reativada permanentemente. Se a otimização não se faz de modo autônomo, já que ela é sempre relacional (sempre ótima em um ranking de outros "ótimos"), ela também não se faz fora de um gerenciamento temporal: a instituição desse "meio" social chamado concorrência vincula-se profundamente ao enfraquecimento da coletividade e à necessidade de antecipar cenários futuros, de saber "ler" o porvir. Ativos sobre os quais o sujeito detém total e completa responsabilidade de gestão: contribuir pelo tempo possível, fazer sua própria poupança, "ingressar o mais rápido no mercado de trabalho" ${ }^{26}$, assumir (desde pequeno) riscos calculados, ser resiliente diante das mudanças, contribuir para diminuir os desastres climáticos, encarar a decadência financeira dos Estados, trabalhar mais anos, encaixar-se no emergente mercado de trabalho. Nessa perspectiva, o risco produz modalidade específica de subjetivação impondo comportamentos, princípios de conduta, desejos e expectativas, fazendo com que o indivíduo precise interiorizar as relações de poder pretensamente imprescindíveis a sua sobrevivência ${ }^{27}$.

Essa economia faz com que o risco adquira caráter virtuoso: não só os “alfabetizados em futuro" ganham vantagem na corrida concorrencial, mas também risk takers que, ao lerem o porvir, se lançam ao perigo, se aproveitam das crises futuras, se aventuram a "correr riscos". A profusão pedagógica em torno da aventura do risco opera inscrevendo na vida cotidiana uma espécie de gradiente hermenêutico acerca desses riscos, formado de curvas móveis de classificação e interpretação, de qualificação e hierarquização: os que devem ser imunizados (e que justificam inúmeras medidas de segurança e múltiplas estratégias de governo de condutas), os que devem ser interpretados como chance de sucesso e os que não devem ser considerados significativos. "Ler o futuro" exige também a criação de grade própria de inteligibilidade. Assim, os riscos servem para manter os mecanismos de concorrência ativos e desiguais entre os indivíduos, mas também entre as diversas ameaças. Melhor: trata-se de produzir

26. Disponível em <http://bit.ly/2GhvJsQ>, consultado em 11/4/2019.

27. Para Byung-Chul Han (2018), o neoliberalismo preocupa-se em agir sobre o psicológico dos sujeitos, para, de forma produtiva, conduzi-los em seus processos psíquicos e mentais em direção a uma busca individual e voluntária pela performance e pelo desempenho. Na "Sociedade do Desempenho" atravessada pela Psicopolítica, o sujeito empreendedor de si conduz, vigia e cobra de si mesmo, tornando-se ponto de operação de sofisticadas formas de controle e exploração subjetivas. Trata-se de uma ação produtiva do poder que vai além dos corpos individuais, da vida biológica ou das populações, mas que age sobre o psicológico dos indivíduos. 
uma distribuição de visibilidades. Hiperiluminada está a profusão discursiva acerca daqueles riscos que legitimam a responsabilização do indivíduo que a governança neoliberal supõe. Por outro lado, invisibilizados os riscos sociais, aqueles produzidos pelo funcionamento do capital, aqueles que para serem, de fato, evitados exigiriam uma reorganização do funcionamento do próprio sistema político-econômico e de suas estratégias de governamentalidade.

Breves conclusões: entre os riscos e os não riscos, um regime de (in)visibilidades

O surgimento de uma nova doença respiratória humana altamente transmissivel e virulenta, para a qual não existem contramedidas adequadas, poderia iniciar uma pandemia global [...]. O surgimento de uma doença pandêmica depende da mutação genética natural ou do agrupamento de cepas de doenças atualmente em circulação ou do surgimento de um novo patógeno na população humana. Especialistas consideram que cepas de influenza aviária altamente patogênica (HPAI), como $H 5 \mathrm{~N} 1$, são provavelmente candidatos a essa transformação, mas outros patógenos como o coronavirus Sars ou outras cepas de influenza - também têm esse potencial. Potential Emergence of a Global Pandemic (Us National Intelligence Council, 2008, p. 75).

Nesse contexto, não parecem surpreendentes as narrativas que argumentam não haver perigo de contaminação nas praias brasileiras depois do gigante vazamento de óleo em 2018, pois nelas estaria tudo "limpo, limpo, limpo" (Uchôa, 2019) ${ }^{28}$. Nem parecem surpreendentes as declarações de que não deveríamos "nos aterrorizar" com o "risco mínimo" de danos futuros provocados pelo uso do agrotóxico ${ }^{29}$. Tampouco seriam novidade os discursos em que o aquecimento global aparece como ficção sensacionalista, ou os anúncios de que as novas doenças virais previstas pelos especialistas são “problemas pequenos" (Watson, 2020) ${ }^{30}$. Ademais, poderá também não ser tão impactante o fato de constar em um dos relatórios do National Intelligence Council (NIC) que circula atualmente na internet, teoricamente elaborado há mais de uma década (Global Trends, 2008), um alerta explícito para a possibilidade de uma pandemia

28. "Do alto, passando de helicóptero, o superintendente do Instituto Brasileiro do Meio Ambiente e dos Recursos Naturais Renováveis (Ibama) na Bahia, Rodrigo Alves, tira uma foto da praia de Garapuá, no litoral sul da Bahia. Em sua conta no Instagram, ele publica a imagem, marca a localização e legenda: 'Limpo limpo limpo limpo'. Lá embaixo, onde não se pode ver em sobrevoo, pescadores e outros moradores se embrenham no mangue e enterram a mão em uma mistura de lama e óleo cru, tentando arrancar à força a substância tóxica que invadiu o ecossistema de onde tiram seu sustento.” (Uchôa, 2019).

29. "Na vida não existe risco zero. Agora o risco é mínimo, e o risco é um risco calculado em que todos os países do mundo trabalham numa mesma tabela, numa mesma análise de risco, para todos os produtos que estão aí, segundo a Ministra brasileira da Agricultura, Tereza Cristina.” (Amorin, 2019).

30. Em uma entrevista coletiva em Washington, o presidente dos Estados Unidos disse que o risco para os americanos "permanece muito baixo" e previu que o número de casos diagnosticados no país (quinze na época) "poderia cair para zero em alguns dias” (Farrer, 2020). 
como a do Covid-19. Embora não tenhamos como garantir a confiabilidade desses documentos com acesso público, neles está previsto para 2025 o surgimento de uma doença pandêmica que "provavelmente ocorrerá primeiro em uma área marcada por alta densidade populacional e estreita associação entre seres humanos e animais, como muitas áreas da China e do Sudeste Asiático, onde as populações humanas vivem em estreita proximidade com o gado" (2008, p. 75).

Aliás, cientistas renomados de diversos campos da biologia, em diferentes países, anunciam hoje - momento em que a pandemia já não pode ser tomada como o enredo de um filme barato, sendo uma absoluta e trágica realidade - que esse alerta vem sendo feito há mais de uma década (ver: Brannen e Hicks, 2020; Carroll et al., 2018). Impossível, portanto, não nos questionarmos acerca da razão de medidas preventivas significativas - como investimento massivo no sistema público de saúde, por exemplo - não terem sido colocadas em prática. Fomos ou não capazes de "ler o futuro"? E o que fazemos com essas "leituras"? Quais ações de fato a atual cultura da prevenção legitima?

Decerto, não foram apenas as medidas de prevenção que não pareceram prioridade na governança neoliberal desde que os primeiros alertas foram divulgados na comunidade científica, há quase dez anos. Ainda hoje, deflagrada e constatada a dimensão global dessa crise sanitária e, mesmo diante do apelo de líderes como o presidente da $\mathrm{OMS}^{31}$, em várias cidades brasileiras, o risco pandêmico continua sendo tratado, pelo menos por alguns governadores, prefeitos, ministros ou pelo próprio presidente, como um não risco para as pessoas (principalmente para os pobres) e um grave risco para a economia. "Enfrentar o vírus como homem, não como moleque" (Ferraz, 2020) deveria ser, segundo o presidente Jair Bolsonaro, um modo de os brasileiros desenvolverem a resiliência necessária para defender seus empregos.

Assim, para concluir, poderíamos dizer que a governamentalidade neoliberal supõe não só a consolidação do risco como esfera da vida de que o sujeito empresarial parece não poder se esquivar (Dardot e Laval, 2016, p. 346). Se "ser empresa de si mesmo" exige contabilizar perigos, calcular prognósticos, minimizar ameaças, viver - enfim - inteiramente em risco, isso significa também ter que lidar, analisar e perpetuar uma certa grade de hierarquização e interpretação desses riscos. Há, portanto, um vínculo estreito entre a produção de um regime de visibilidades do risco, a privatização do destino e o esvaziamento da dimensão política e social da imaginação e da construção de futuros. Como argumenta Lazzarato (2017, p. 21), o

31. Em entrevista coletiva, o chefe da OMS alerta para a gravidade da pandemia: “'Confie em nós. O pior ainda está à nossa frente', disse Tedros. 'Vamos impedir essa tragédia. É um vírus que muitas pessoas ainda não entendem.” (Global News, 2020). 
que é expropriado pelo neoliberalismo não é apenas a riqueza ou o mesmo o futuro; o que nos é subtraído, mais fundamentalmente, é o possivel - "a primeira palavra do neoliberalismo é 'não há alternativa', não há outras possibilidades além daquelas enunciadas pelo mercado e pela finança”.

Fica, então, a pergunta quanto à possibilidade de nossa capacidade tecnocientífica de prever as ameaças estar articulada a uma crítica profunda dessa governamentalidade atual; articulada, portanto, a outra economia do porvir. A violência com que a pandemia tem atingido o mundo e, com mais intensidade, as populações vulneráveis, periféricas, negras e faveladas, nos faz suspender o ritmo acelerado, o presente contínuo e ampliado, em que vivemos há décadas. A crise, de certo, recoloca um não saber diante do porvir. Reintroduz a virtualidade do tempo: a possibilidade de pensarmos outros sentidos para o destino de nossa sociedade. Abertura que a todo momento está sujeita à invenção de inéditos modos de controle, formas “inovadoras" de vigilância e também tecnologias ainda mais avançadas e "eficientes" de prevenção que prometem, agora sim, ser capazes de nos livrar de todo mal. Resta saber se seremos capazes de pensar politicamente esses “usos do futuro”. Ampliar e (quem sabe) revitalizar o possível.

\section{Referências Bibliográficas}

Adam, B. \& Groves, C. (2007), Future matters: action, knowledge, ethics. Leiden, Brill.

Adams, Tim. (11/12/2015), "My father had one job in his life, I’ve had six in mine, my kids will have six at the same time". The Guardian. Disponível em <http://bit.ly/2IsU8x9>, consultado em 27/04/2020.

Agamben, G. (2009), “O que é um dispositivo”. In: O que é o contemporâneo e outros ensaios. Chapecó, Argos.

Agamben, G. (25/01/2019), Intervenção no programa Chiodo Fisso da rádio Rai 3. Disponível em http://bit.ly/2WmLRPi, consultado em 03/05/2019.

Amara, R. (1974), “The futures field: functions, forms, and critical issues”. Futures, 6 (4): 289-301.

Amorin, Felipe. (06/08/2019), “'Não podemos aterrorizar' sobre agrotóxicos, diz ministra da Agricultura”. UOL. Disponível em <https://bit.ly/2S8eeRr>, consultado em 27/04/2020.

ArizA, Luiz Miguel. (14/02/2019), "Exame de sangue detecta tumores 15 anos antes de seu surgimento”. El País. Disponível em <http://bit.ly/2D9lMMh>, consultado em 27/04/2020.

BAUdrillard, Jean. (1991), Simulacros e simulação. Lisboa, Relógio D’Água.

Baumgartner, Natalie. (11/04/2019), "Change is the new normal: how to build a resilient work place”. Forbes. Disponível em <http://bit.ly/2UeSCkk>, consultado em 27/04/2020. 
Bell, Wendell. (1997), Foundations of futures studies, 2 vols. (History, Purposes, knowledge; values, objectivity, and the good society). New Brunswick, Transaction Publishers.

Beck, U. (2010), Sociedade de risco: rumo a uma outra modernidade. São Paulo, Editora 34.

BRANNER, Samuel \& Hicks, Kathleen. (07/03/2020), "We predicted a coronavirus pandemic. Here's what policymakers could have seen coming”. Politico. Disponível em $<$ https://politi. co/2AdNWqU>, consultado em 27/04/2020.

Bruno, F. (2013), Máquinas de ver, modos de ser: vigilância, tecnologia e subjetividade. Porto Alegre, Sulinas.

Carroll, Dennis et al. (2018), “The global virome project”. Science, 359 (6378): 872-874.

Castro-Gómez, Santiago. (2010), Historia de la gubernamentalidad. Razón de Estado, liberalismo y neoliberalismo en Michel Foucault/Santiago Castro-Gómez. Bogotá, Siglo del Hombre Editores/Pontificia Universidad Javeriana/Instituto Pensar/Universidad Santo Tomás de Aquino.

DARDot, Pierre \& Laval, Christian. (2016), A nova razão do mundo: ensaio sobre a sociedade neoliberal. São Paulo, Boitempo.

Defert, Daniel. (1991), “Popular life” and insurance technology”. In: Burchell, G; GorDON, C. E. \& MilleR, P. (orgs.). The Foucault effect: studies in governmentality. Chicago, The University of Chicago Press.

Deleuze, G. (1996), “O que é um dispositivo?”. In: O mistério de Ariana. Lisboa, Vega, pp. 83-96.

DUNKer, Christian. (2015), Mal-estar, sofrimento e sintoma: uma psicopatologia do Brasil entre muros. São Paulo, Boitempo.

Dunker, Christian. (25/04/2016), Neoliberalismo e sofrimento psíquico [Arquivo de vídeo]. Disponível em <http://bit.ly/2va5xKn>, consultado em 27/04/2020.

Epsc (European Political Strategy Centre). (2016), “The future of work: Skills and resilience for a world of change". EPSC Strategic Notes. Luxembourg, Publications Office of the European Union, issue 13. Disponível em <http://bit.ly/2ZnIl9c >, consultado em 27/04/2020. Escola Concept. (2018), Digital fluency - Escola Concept is awarded as an Apple Distinguished School. Disponível em <https://bit.ly/2X2NC5h>, consultado em 13/02/2019.

Ewald, François. (1991), “Insurance and risk”. In: BurChell, G; Gordon, C. E. \& Miller, P. (orgs.). The Foucault effect: studies in governmentality. Chicago, The University of Chicago Press. FARrer, Martin. (27/02/2020), “Coronavirus: Trump says Us risk 'very low' as Australian PM warns pandemic is 'upon us'. The Guardian. Disponível em <https://bit.ly/3eQtP1w>, consultado em 27/04/2020.

Ferraz, Adriana. (29/03/2020), "Bolsonaro diz que é preciso 'enfrentar vírus como homem e não como moleque'”. UOL. Disponível em <https://bit.ly/3aAu5yx >, consultado em 27/04/2020.

Foresight ALLIANCE, Foresightalliance.com. Disponível em <http://bit.ly/2UrAFzk >, consultado em 05/05/2019. 
Foucault, Michel. (1988), História da sexualidade I: a vontade de saber. 13 ed. Rio de Janeiro, Graal.

Foucault, Michel. (1999), Em defesa da sociedade: curso no Collège de France (1975-1976). São Paulo, Martins Fontes.

Foucault, Michel. (2006), “A 'governamentalidade”. In: Foucault, Michel. Ditos \& escritos: estratégia, poder-saber. vol. 4. Rio de Janeiro, Forense Universitária, pp. 281-305.

Foucault, Michel. (2008a), Nascimento da biopolítica. Curso no Collége de France: 1978-1979. São Paulo, Martins Fontes.

Foucault, Michel. (2008b), Segurança, território, população. Curso no Collège de France: 1977 1978. São Paulo, Martins Fontes.

"Futures Literacy", Unesco.org, <http://bit.ly/2GpjMQV>, consultado em 12/04/2019.

Giddens, Anthony. (2009), The politics of climate change. Cambridge, Polity Press.

GLOBAL NEWS. (21/04/2020), “Worst is yet ahead of us' in coronavirus outbreak, WHO warns”. Global News. Disponível em <https://bit.ly/2yLFIW4>, consultado em 27/04/2020

Han, Byung-Chul. (2018), Psicopolitica: o neoliberalismo e as novas técnicas de poder. Belo Horizonte, Âyiné.

Hartog, François. (2013), Regimes de historicidade: presentismo e experiências do tempo. Belo Horizonte, Autêntica

HöLsCHer, Lucian. (2014), El descubrimento del futuro. Trad. Carlos Martín Ramírez. Madri, Siglo XXI.

Koselleck, Reinhart. (2006), Futuro passado: contribuição semântica dos tempos históricos. Rio de Janeiro, PUC.

Lazzarato, M. (2017), O governo do homem endividado. São Paulo, n-1.

Martello, Alexandro. (20/02/2019), "Previdência: capitalização vai assegurar aposentadoria de pelo menos um mínimo, diz governo”. G1, Brasília. Disponível em: <https://glo. bo/2Z7pbV1>, consultado em 25/04/2020.

Mec, Ministério da Educação (2017), Com o Novo Ensino Médio, você tem mais liberdade para escolher o que estudar! Propaganda governamental da reforma do Ensino Médio (Lei n. 13.415, promulgada em 16 de fevereiro de 2017). Disponível em <http://bit.ly/2GhvJsQ>, consultado em 11/04/2019.

Miller, Riel. (2018), Transforming the future: anticipation in the 21st Century. Paris, Unesco. Minors, George. (1989), History of Old Age. Cambridge, Polity Press.

Niemtus, Zofia. (22/01/2019), Jobs of the future: are you ready to join in? The Guardian. Disponível em: <http://bit.ly/2DaOTib>, consultado em 27/04/2020.

Nowotny, H. (1994), Time: the modern and postmodern experience. Cambrigde, Polity Press. O’Malley, Pat. (1996), “Risk and responsibility”. In: BArry, Andrew; Osborne, Thomas \& Rose, Nikolas (eds.). Foucault and political reason. Londres, University of Chicago Press, pp. 189-209. 
OnP - Oficina de Normalización Previsional. (2015), ONP - Afiliate a un Sistema de Pensiones, Propaganda do Sistema Nacional de Pensões, Peru. Disponível em <http://bit. ly/2UHmASD>, consultado em 13/02/2019.

Palmer, Annie. (11/01/2019), “The AI that will tell you how your face will age: Olay reveals app that can analyze your skin from a selfie and show you how you'll look in 20 years". Dailymail.com. Disponível em <https://dailym.ai/2USX6By>, consultado em 27/04/2020.

Pessoa, Mirella. (2020), Faces do futuro: imagens da velhice no regime de visibilidade contemporâneo. Brasília, DF, dissertação de mestrado, Universidade de Brasília.

Polak, Fred. ([1955] 1973), The image of the future. Amsterdan, Elsevier.

"Reforma da Previdência: proposta do governo incluirá capitalização, diz Paulo Guedes" ( $G 1$, 2018). Disponível em <https://glo.bo/2UcSPo6>, consultado em 5/5/2019.

"Proposta da Nova Previdência é melhor para o Brasil". Site oficial do governo federal brasileiro. Disponível em: <http://bit.ly/2t21C4K>, consultado em 25/04/2020.

ReID, Julian. (2012), “The disastrous and politically debased subject of resilience”. Development Dialogue, 58: 67-79.

Robertson, Katie. (04/12/2018), "Why the world needs to rethink retirement". The New York Times. Disponível em <https://nyti.ms/2InlSTX>, consultado em 27/04/2020.

RoHRBECK HEGER. Strategic foresight + innovation. (2014), Disponível em: <http://bit. ly/2KKwPS5>, consultado em 5/5/2019.

Rosa, Hermut. (2019), Aceleração: a transformação das estruturas temporais na modernidade. São Paulo, Unesp.

Rose, Nikolas. (1989), Governing the soul: The shaping of the private self. Londres, Routledge. SANZ, Cláudia Linhares. (2019a), "Biopolíticas do futuro". Conferência ministrada no seminário internacional Imagem, Tecnologia e Subjetividade, unB. Disponível em <https://bit. ly/3eW $4 \mathrm{ZgV}>$, consultado em: 03/04/2020.

SANZ, Cláudia Linhares. (2019b), "Future-se, porque quem o futuro faz é você: relações contemporâneas entre educação e responsabilização do porvir". In: DRAVET, Florence et al. Transdisciplinaridade e educação do futuro. Brasília, Cátedra Unesco de Juventude, Educação e Sociedade/Universidade Católica de Brasília.

SANZ, Cláudia Linhares \& PESsoA, Mirella. (2020 no prelo), "Vigiar a velhice, vigiar o futuro: tecnologia, antecipação e governo de condutas". Contemporânea: comunicação e cultura. Salvador: PósCom-ufBA.

Senado Notícias. (16/02/2017), “Sancionada Lei da Reforma no Ensino Médio”. Senado Notícias. Disponível em: <http://bit.ly/2GguU3E>, consultado em 27/04/2020.

Us National Intelligence Council. (Nov. 2008), Global Trends 2025: A transformed world. (Report No 2008-003). Washington, DC, us Government Printing Office. Disponível em <https://bit.ly/3c7AzWl>, consultado em 27/04/2020.

Us National Intelligence Council. (Jan. 2017), Global Trends: Paradox of progress. (Report n. 
2017-001). Washington, DC, us Government Printing Office. Disponível em <https://bit. ly/2YaDbPK>, consultado em 27/04/2020.

Uсно̂A, Victor. (01/11/2019), “De 'limpo’ a 'tem muito óleo’: as duas realidades paralelas na crise do petróleo do Nordeste”. BBC News Brasil. Disponível em <https://bbc.in/3bA84B6>, consultado em 27/04/2020.

UnEsCo. Transforming the future: anticipation in the 21stcentury, vídeo. Disponível em <http:// bit.ly/2GfUS7k>, consultado em 05/05/2019.

URrY, John. (2016), What is the future? Cambridge, Polity.

XQ America. (2015), Propaganda de divulgação do XQ Super School Project The future of our schools: an urgency for change. Disponível em <http://bit.ly/2GiHfo4>, consultado em 11/04/2019.

WALLACE-WeLls, David. (16/02/2019), “Time to panic: the planet is getting warmer in catastrophic ways. And fear may be the only thing that saves us". The New York Times. Disponível em <https://nyti.ms/2WXfxCy>, consultado em 27/04/2020.

Watson, K. (03/04/2020), "A timeline of what Trump has said on coronavirus". CBS News. Disponível em <https://cbsn.ws/2VAl9oz>, consultado em 27/04/2020.

\section{Resumo}

Imagens do futuro: risco e responsabilização na gerência neoliberal do amanhã

Fenômeno histórico e global, o senso contemporâneo de futuro se afasta, em vários sentidos, daquele experimentado em outros (futuros) passados. Atuando como uma espécie de máquina na biopolítica dos possíveis, tem efeitos capilares no cotidiano do sujeito. Trata-se de uma hipervisibilidade do futuro em que imagens pretensamente precisas participam da instalação da antecipação como um programa geral necessário à cultura do risco. Nessa governamentalidade neoliberal, entretanto, nem todos os riscos previstos podem (ou devem) ser visíveis: um gradiente hermenêutico acerca desses riscos e "não riscos" instala-se na vida cotidiana. Realidade que enfraquece as coletividades e reduz o espectro do possível aos diagramas econômicos do capitalismo tardio. Palavras-chave: Imagens do futuro; Antecipação; Risco; Responsabilização; Neoliberalismo.

\section{Abstract}

Images of the future. Risk and responsibilization in neoliberal management of the future A historical and global phenomenon, the contemporary sense of the future distances itself, in many ways, from that experienced by other past futures. Acting as a type of bio-political machine of the possible, it has the most minute effects on subject's daily life. A hypervisibility of the future where the pretentiously precise images participate in the installation of anticipation as a general program in the culture of risk. In this neoliberal governmentality, however, not all predicted risks 
can (or should) be visible: a hermeneutic gradient about these risks and non-risks is installed in everyday life. Reality that weakens collectivities and reduces the spectrum of the possible to economic diagrams of late capitalism

Keywords: Images of the future; Anticipation; Risk; Responsibilization; Neoliberalism.

Texto recebido em 31/07/2019 e aprovado em 16/05/2020.

DOI: $10.11606 / 0103-2070 . t s .2020 .160462$.

Claudia Linhares Sanz é professora da Universidade de Brasília. Fez pós-doutorado no Zentrum für Literatur-und Kulturforschung ( $\mathrm{zfL}$ ), em Berlim, desenvolvendo a pesquisa Images of the future and contemporary education (2017/2018). Líder do grupo de pesquisa Imagem, Tecnologia e Subjetividade (CNPq). Doutora em Comunicação pela Universidade Federal Fluminense com pesquisa no Instituto Max Plank de História da Ciência em Berlim. E-mail: claudialinharessanz@gmail.com.

Mirella Pessoa é doutoranda pelo Programa de Pós-graduação em Comunicação da UfPe e mestre pelo Programa de Pós-graduação em Comunicação da Universidade de Brasília, onde apresentou o trabalho Faces do futuro: imagens da velhice no regime de visibilidade contemporâneo, desenvolvido com apoio financeiro de bolsa da Coordenação de Aperfeiçoamento de Pessoal de Nível Superior (Capes). Faz parte do grupo de pesquisa Imagem, Tecnologia e Subjetividade (CNPq).E-mail:mihpessoa@gmail.com. 